\title{
Appropriateness of colonoscopy in Europe (EPAGE II) Chronic diarrhea and known inflammatory bowel disease
}

Authors

Institutions
S. Schusselé Filliettaz ${ }^{1}$, P. Juillerat ${ }^{2}$, B. Burnand ${ }^{1}$, C. Arditi ${ }^{1}$, A. Windsor ${ }^{3}$, C. Beglinger ${ }^{4}$, R. W. Dubois ${ }^{5}$, I. Peytremann-Bridevaux ${ }^{1}$, V. Pittet ${ }^{1}$, J.-J. Gonvers ${ }^{2}$, F. Froehlich ${ }^{2,4}$, J.-P. Vader ${ }^{1}$ and the EPAGE II Study Group ${ }^{6}$

Institutions are listed at the end of article. submitted 17 June 2008 accepted after revision 5 December 2008

Bibliography

Dol $10.1055 / \mathrm{s}-0028-1119627$

Endoscopy 2009; 41:

218-226 @ Georg Thieme Verlag KG Stuttgart · New York ISSN 0013-726X

\section{Corresponding author} J.-P. Vader, MD MPH Institute of Social and Preventive Medicine Rue du Bugnon 17 $\mathrm{CH}-1005$ Lausanne Switzerland Fax: +41-21-3144954 john-paul.vader@chuv.ch
Background and study aims: To summarize the published literature on assessment of appropriateness of colonoscopy for investigation of chronic diarrhea, management of patients with known inflammatory bowel disease (IBD), and for colorectal cancer (CRC) surveillance in such patients, and to report report appropriateness criteria developed by an expert panel, the 2008 European Panel on the Appropriateness of Gastrointestinal Endoscopy, EPAGE II.

Methods: A systematic search of guidelines, systematic reviews, and primary studies regarding the evaluation of chronic diarrhea, the management of IBD, and colorectal cancer surveillance in IBD was performed. The RAND/UCLA Appropriateness Method was applied to develop appropriateness criteria for colonoscopy for these conditions.

Results: According to the literature, colonoscopic evaluation may be justified for patients aged $>50$ years with recent-onset chronic diarrhea or with alarm symptoms. Surveillance colonoscopy for CRC should be offered to all patients with exten-

\section{Introduction \\ $\nabla$ \\ Chronic diarrhea \\ Chronic diarrhea is defined by a duration of $>4$ weeks and $>3$ loose stools/day [1]. Chronic diar- rhea can have organic as well as functional causes. The most frequent organic origins identified in these patients include inflammatory bowel dis- ease (IBD) $(7 \%-14 \%)$, infectious causes $(11 \%-$ $15 \%)$, malabsorption $(3 \%-5 \%)$, and drug use $(4 \%-10 \%)[2-4]$.}

\section{Known inflammatory bowel disease}

Ulcerative colitis is characterized by diffuse continuous mucosal inflammation limited to the colon. The main symptom of ulcerative colitis is bloody diarrhea [5,6]. Based upon clinical and endoscopic findings, ulcerative colitis is character- sive ulcerative colitis or colonic Crohn's disease of 8 years' duration, and to all patients with less extensive disease of 15 years' duration. Intervals for surveillance colonoscopy depend on duration of evolution, initial diagnosis, and histological findings. The EPAGE II criteria also confirmed the appropriateness of diagnostic colonoscopy for diarrhea of $>4$ weeks' duration. They also suggest that, in addition to assessing extent of IBD by colonoscopy, further colonoscopic examination is appropriate in the face of persistent or worsening symptoms. Surveillance colonoscopy in IBD patients was generally appropriate after a lapse of 2 years. In the presence of dysplasia at previous colonoscopy, it was not only appropriate but necessary.

Conclusions: Despite or perhaps because of the limitations of the available published studies, the panel-based EPAGE II (http://www.epage.ch) criteria can help guide appropriate colonoscopy use in the absence of strong evidence from the literature.

ized as to its severity and extent [5-8]. Symptoms of Crohn's disease are heterogeneous, commonly including diarrhea [5,9]. Crohn's disease encompasses a spectrum of clinical and pathological patterns manifested by inflammation affecting various sites in the gastrointestinal tract with the potential for systemic and extraintestinal complications $[5,10]$. Crohn's disease may be defined by location, by pattern of disease, by disease activity, by response to therapy, and by immunological features (see the Vienna and Montreal classifications) $[9,11-16]$.

Diagnosis of IBD mainly relies on symptoms and is then confirmed by clinical evaluation and a combination of investigations, including endoscopy $[6,9,10,17,18]$. Until recently, complications of bowel ulceration prompted treatment and/or surgery, thus inducing temporary clinical remission. 
New biological treatments now aim at halting the progression of the disease and at attaining complete mucosal healing as well as clinical remission. Therapeutic approaches to IBD are presented in a companion article [19].

Long-standing ulcerative colitis and Crohn's disease are associated with development of colorectal dysplasia and cancer, but the exact magnitude of the risk is not clearly defined [20-32] (see also Results section Surveillance colonoscopy in known IBD). Recent studies suggest that colorectal cancer (CRC) in IBD may be less frequent than was previously believed. This could partly be due to effective therapy and prevention strategies $[33,34]$. The main established risk factors for CRC in IBD include prolonged disease duration [23,35], extensive colonic involvement [36], and family history of CRC [37]. The macroscopic features of intraepithelial neoplasia are heterogeneous, ranging from flat to plaque-like and mass or polypoid lesions ("dysplasia-associated lesion or mass [DALM]") to strictures. Overall, $60 \%-70 \%$ of these lesions are visible during conventional colonoscopy. The evolution of low-grade dysplasia is still unclear [31,41-44]. Although colonoscopic surveillance programs are available, ulcerative colitis or Crohn's colitis are situations in which the optimal method of prevention of cancer-related mortality is still unclear $[45,46]$. In April 2008, a multidisciplinary European expert panel convened in Montreux, Switzerland, to discuss and develop criteria for the appropriate use of colonoscopy. This article presents the literature review, on the use of colonoscopy, in chronic diarrhea, known IBD, and surveillance for CRC in IBD patients, that was provided to the panelists before the panel meeting to support their ratings of appropriateness of use of colonoscopy in such circumstances, which are also reported here. It is an update of a previous literature review and appropriateness criteria published in $1999[47,48]$.

In the first topic of this article, uncomplicated chronic diarrhea will be considered. In this context, "uncomplicated" is taken to mean that an infectious or malabsorption origin or laxative abuse has been excluded. The patients considered for colonoscopic evaluation in this context would also have no risk factor for CRC, except for age, and none of the following so-called alarm or "red flag" symptoms: hematochezia; positive fecal occult blood test (FOBT); anemia; personal/family history of colon cancer; personal/family history of inflammatory bowel disease; weight loss of $\geq 5 \mathrm{~kg}$; fever; abdominal mass; or HIV/AIDS [49]. In the second topic treated in this article, the use of colonoscopy for management and follow-up of known IBD (i.e., ulcerative colitis and Crohn's disease), as well as the evaluation of strictures and CRC surveillance in ulcerative colitis and Crohn's disease, will be reviewed. Initial diagnosis of IBD will not specifically be addressed: patients presenting symptoms suggestive of IBD but not yet diagnosed are dealt with under the previous topic of chronic diarrhea.

\section{Methods}

The literature review process included a systematic search of websites issuing guidelines and of Medline (1997-February 2008) to select published guidelines, systematic reviews, and primary studies assessing the use of colonoscopy in patients with chronic diarrhea and in known IBD. With the exception of certain relevant articles, the literature published before 1997 is presented in the previous literature review $[47,48]$.

The application of the RAND/UCLA Appropriateness Method is described in a companion article in this issue [50]. Briefly, the
RAND process is a formal explicit expert panel method that allows classification of each indication into one of the following categories of appropriateness: inappropriate, uncertain, appropriate, and both appropriate and necessary (i.e. the indication mandates colonoscopy). To simplify the graphical presentation of the appropriateness results, these four categories were consolidated into two clusters: "Appropriate" (comprising the two categories appropriate and appropriate and necessary) and "Not appropriate" (comprising categories inappropriate and uncertain). In addition to simplification and enhanced clarity of presentation, the rationale for this choice was that in many instances in the case of a nonappropriate scenario, whether it be uncertain or inappropriate, the decision for not proposing the colonoscopy should be specifically discussed and shared with the patient. All clinical indications and their ratings are available on the EPAGE website (www.epage.ch).

\section{Results: Literature review}

$\nabla$

\section{Chronic diarrhea}

A total of 18 primary studies investigating the diagnostic yield of colonoscopy in patients presenting chronic diarrhea and published between 1997 and February 2008 were identified. Nine guidelines published over the same period and giving recommendations on the use of colonoscopy for diagnostic purposes in these patients were retrieved.

Primary studies [51-68] investigating the diagnostic yield of lower gastrointestinal endoscopy in chronic diarrhea (Table e1) show wide variation in rates, with findings ranging from $15 \%$ up to $70 \%$ of the cases. Microscopic colitis $[64,69]$ (both collagenous colitis and lymphocytic colitis) was diagnosed in $10 \%-14 \%$ of patients investigated endoscopically for chronic diarrhea. Guidelines [1,2,70 - 74] (Table e2) offer no clear consensus on the appropriateness of endoscopic procedures in chronic diarrhea. If an endoscopic procedure is performed, it is not clear whether the initial procedure should be sigmoidoscopy or colonoscopy, although some guidelines clearly recommend colonoscopy at $>50$ years of age [70]. In the event of an endoscopic investigation, multiple biopsies should be taken - including in the ileum, except when the latter is macroscopically normal - but there is no clear consensus on their exact location and on the number of biopsies to be taken. There seems to be a trend towards the taking of multiple biopsies, ideally in the descending colon, especially when looking for microscopic colitis $[69,75]$.

Practitioners might consider performing colonoscopy in the presence of chronic diarrhea mainly with the aim of excluding CRC. In the retrieved primary studies [76-78] (Table e3), chronic diarrhea does not appear to constitute an indicator or a risk factor for colonic neoplasia. Some CRC screening/surveillance guidelines $[70,71,74]$ do cite diarrhea as a possible symptom which might indicate CRC, while the majority of the retrieved screening/surveillance guidelines do not even mention diarrhea[7988] . Only the French guidelines from ANAES (Agence Nationale d'Accréditation et d'Evaluation en Santé) [70] recommend that, for patients with diarrhea of recent onset and unresponsive to treatment, a total colonoscopy be performed to identify a potential colonic neoplasm if symptoms appear in an individual $>50$ years of age, or if symptoms appear at younger than $<50$ years of age and if symptomatic treatment is not effective. 
Table 8 Definitions related to chronic diarrhea, evaluation of known ulcerative colitis or Crohn's disease, and to surveillance for colorectal cancer in inflammatory bowel disease.

\begin{tabular}{|c|c|c|}
\hline & Term & Definition \\
\hline \multirow[t]{5}{*}{ Chronic diarrhea } & Uncomplicated diarrhea & $\begin{array}{l}\text { Diarrhea with one or more of the following: }>3 \text { loose stools/day, infectious or } \\
\text { malabsorption origin excluded, without known IBD, no anemia, no bleeding, no } \\
\text { risk factors for CRC, no HIV/AIDS, chronic diarrhea } \geq 4 \text { weeks' duration }\end{array}$ \\
\hline & Infection work-up & $\begin{array}{l}\text { Stool culture for enteric pathogens and examination for ova and parasites, im- } \\
\text { munoassay for Clostridium difficile toxin if patient was taking antibiotics within } 2 \\
\text { weeks prior to onset of diarrhea }\end{array}$ \\
\hline & $\begin{array}{l}\text { Lower gastrointestinal } \\
\text { investigations }\end{array}$ & $\begin{array}{l}\text { Sigmoidoscopy or barium enema since onset of lower abdominal pain or within } \\
\text { past } 5 \text { years }\end{array}$ \\
\hline & Barium enema & $\begin{array}{l}\text { Double-contrast technique (in some countries barium enema may still be used } \\
\text { widely, in particular in patients with nonspecific abdominal symptoms) }\end{array}$ \\
\hline & Sigmoidoscopy & Flexible tube $(60 \mathrm{~cm})$ \\
\hline \multirow[t]{5}{*}{ Known ulcerative colitis } & Ulcerative colitis & $\begin{array}{l}\text { Documented by one or more of the following: endoscopic appearance, mucosal } \\
\text { biopsy, operative report with pathology AND infectious cause excluded }\end{array}$ \\
\hline & Extension of ulcerative colitis & $\begin{array}{l}\text { Evaluation of the extension of the disease (proctitis, pancolitis, left-sided colitis) } \\
\text { with no previous colonoscopy done }\end{array}$ \\
\hline & Previous investigation & $\begin{array}{l}\text { Sigmoidoscopy performed within the last } 3 \text { months and since symptoms began, } \\
\text { recurred or worsened. }\end{array}$ \\
\hline & Sigmoidoscopy & Flexible tube $(60 \mathrm{~cm})$ \\
\hline & Current therapy & $\begin{array}{l}\text { Daily treatment for at least } 14 \text { days with one or more of the following: } 5 \text {-aminosa- } \\
\text { licylic acid (5-ASA; enema, suppositories or oral), sulfasalazine, topical steroids } \\
\text { OR daily prednisone for at least } 2 \text { weeks OR daily treatment with one of the fol- } \\
\text { lowing for at least } 60 \text { days: azathioprine, cyclosporin, 6-mercaptopurine (6-MP), } \\
\text { methotrexate, tacrolimus, infliximab. }\end{array}$ \\
\hline \multirow[t]{4}{*}{ Known Crohn's disease } & Crohn's disease & $\begin{array}{l}\text { Documented by one or more of the following: endoscopic appearance, mucosal } \\
\text { biopsy, radiography, operative report with pathology AND infectious cause ex- } \\
\text { cluded }\end{array}$ \\
\hline & Extension of Crohn's disease & Evaluation of the extension of the disease with no previous colonoscopy done. \\
\hline & Previous investigation & $\begin{array}{l}\text { Small-bowel follow-through (SBFT) or entero-CT/MRI (computed tomography/ } \\
\text { magnetic resonance imaging) performed within the last } 3 \text { months and since } \\
\text { symptoms began, recurred or worsened }\end{array}$ \\
\hline & Current therapy & $\begin{array}{l}\text { Daily treatment for at least } 14 \text { days with one or more of the following: 5-ASA (en- } \\
\text { ema, suppositories or oral), sulfasalazine, or topical steroids OR daily prednisone } \\
\text { or budesonide for at least } 2 \text { weeks OR daily treatment with one of the following for } \\
\text { at least } 60 \text { days: azathioprine, cyclosporine, 6-MP, tacrolimus, methotrexate, anti- } \\
\text { tumor necrosis factor (TNF) agents (infliximab, adalimumab, certolizumab). }\end{array}$ \\
\hline \multirow{4}{*}{$\begin{array}{l}\text { Surveillance for colorectal cancer } \\
\text { (CRC) in inflammatory bowel } \\
\text { disease (IBD) }\end{array}$} & Ulcerative colitis & $\begin{array}{l}\text { Documented by one or more of the following: endoscopic appearance, mucosal } \\
\text { biopsy, operative report with pathology AND infectious cause excluded }\end{array}$ \\
\hline & Crohn's disease & $\begin{array}{l}\text { Documented by one or more of the following: endoscopic appearance, mucosal } \\
\text { biopsy, radiography, operative report with pathology AND infectious cause ex- } \\
\text { cluded }\end{array}$ \\
\hline & Low-grade dysplasia & $\begin{array}{l}\text { Low degree of a combination of architectural and cytological alterations such as } \\
\text { gross distortion, hyperchromasia, enlarged nuclei, large nucleoli, loss of cellular } \\
\text { polarity confined within the basement membrane of the glands in which it arose }\end{array}$ \\
\hline & High-grade dysplasia & High degree of architectural and cytological alterations \\
\hline
\end{tabular}

\section{Known inflammatory bowel disease (IBD)}

Nine guidelines on the use of colonoscopy for clinical management of patients with known IBD and published between 1997 and February 2008 were identified. For the same period, 19 guidelines were retrieved on the use of colonoscopy for surveillance for CRC in these patients.

Colonoscopy in clinical management in known IBD. Guidelines $[5,6,9,10,18,89-92]$ issuing recommendations on the use of colonoscopy for clinical management purposes (surveillance excluded) in known ulcerative colitis and Crohn's disease are presented in Table e4 and Table e5. In management of known ulcerative colitis, sigmoidoscopic rather than colonoscopic evaluation may be used to define disease activity or assess superimposed colitis. However, the appropriateness of this detection mode depends upon the evolution of the disease and on the potential con- sequences in terms of therapeutic approach. A colonoscopy is useful in the elective preoperative phase. Management of known Crohn's disease does not systematically require colonoscopic procedures, either for evaluation of treatment, or after a new relapse. Colonoscopic procedures are useful for the examination or for the management of short accessible strictures and of bleeding; a colonoscopy is useful in the elective preoperative phase. Surveillance colonoscopy in known IBD. According to the retrieved guidelines [5,6, 9, 18,21,70,73,80,81,83,88-91,93-97] (Table e6), surveillance colonoscopy should be offered:

- to all patients with extensive ulcerative colitis or colonic Crohn's disease of 8 years' duration;

- to all patients with less extensive disease of 15 years' duration; 
Diarrhea for $<4$ weeks

Diarrhea for $\geq 4$ weeks

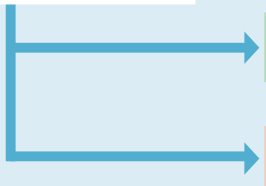

No investigation or

colonoscopy prior to onset of diarrhea

Colonoscopy with biopsies since onset of diarrhea, not explaining diarrhea

Not appropriate

(inappropriate or uncertain)

Appropriate

(and possibly necessary)

Fig. 1 a Appropriateness ratings of clinical indications for performing colonoscopy in patients with uncomplicated chronic diarrhea (simplified decision tree). Copyright (c) 2008 IUMSP/CHUV, Lausanne, Switzerland EPAGE II.

to all patients with IBD-associated primary sclerosing cholangitis.

The literature appears to favor surveillance colonoscopy every 3 years for 10 years, every 2 years for 10 years, and then annually, depending on the decade of evolution. This procedure should include at least 4 biopsies taken randomly every $10 \mathrm{~cm}$ throughout the colon plus biopsy of any macroscopic lesion. Meta-analyses, reviews and studies on the association between IBD and CRC are shown in Table e7.

\section{Results: EPAGE II panel}

$\nabla$

Of the 463 indications examined by the EPAGE II panel, 6 concerned chronic diarrhea, 27 the evaluation of ulcerative colitis, 23 the evaluation of Crohn's disease, and 43 the use of colonoscopy for CRC surveillance in IBD. The number of scenarios (indications) considered inappropriate in each of these clinical categories was 2, 15, 9 and 15 respectively. Frank disagreement among the expert panelists was low (11\% of scenarios). Indications considered necessary (mandating colonoscopy) were concentrated mainly in the group of CRC surveillance, especially when previous colonoscopy had revealed any grade of dysplasia or in presence of long-standing disease.

- Table 8 shows the definitions used for the clinical categories.

- Fig. 1 a, 2 a, 3 a, and 4 a summarize appropriateness of colonoscopy consolidated into two categories: "Not appropriate" (comprising categories uncertain and inappropriate) versus "Appropriate" (including necessary).

As in the literature review, the EPAGE II panel criteria confirmed the appropriateness of diagnostic colonoscopy for diarrhea of at least 4 weeks' duration ( $\bullet$ Fig. 1 a). They also recommend that in addition to assessment of the extent of IBD by colonoscopy, colonoscopic examination is appropriate in the face of persistent or worsening symptoms ( $\bullet$ Figs. $\mathbf{2 a}$ and $\mathbf{3 a}$ ), with some nuances for ulcerative colitis depending on the existence and nature of prior sigmoidoscopy findings. The indication for surveillance co-

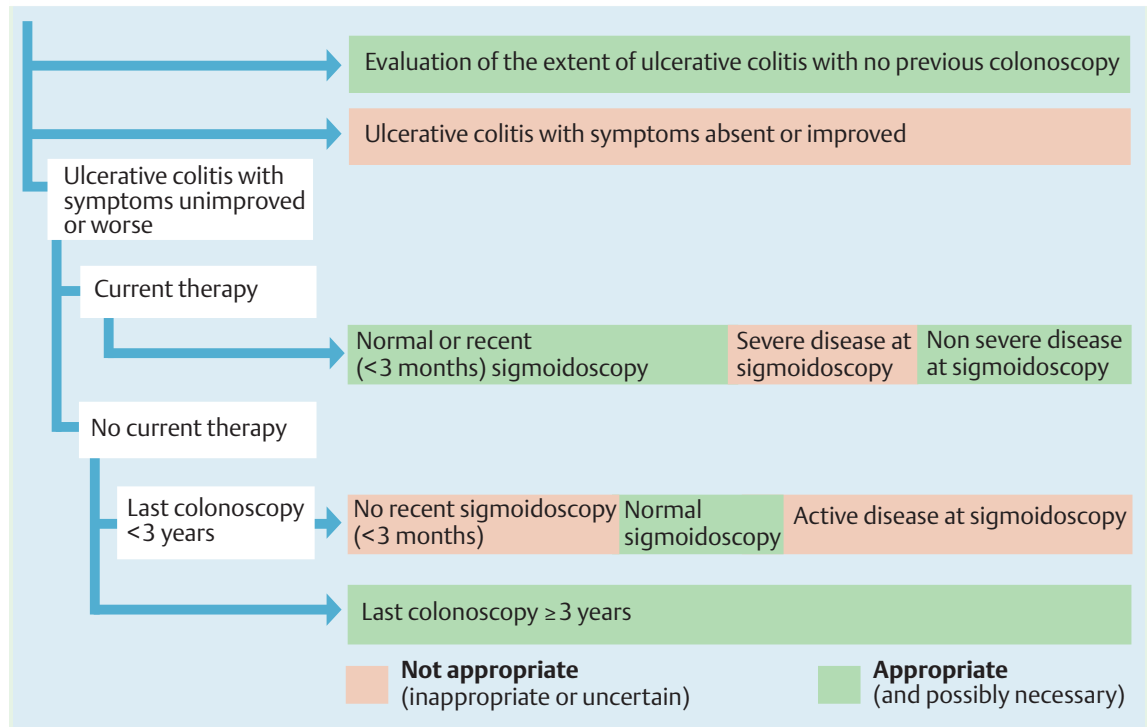

Fig. 2a Appropriateness ratings of clinical indications for performing colonoscopy in patients for the evaluation of known ulcerative colitis, excluding surveillance for colorectal cancer (simplified decision tree). Copyright $\odot 2008$ IUMSP/CHUV, Lausanne, Switzerland - EPAGE II.

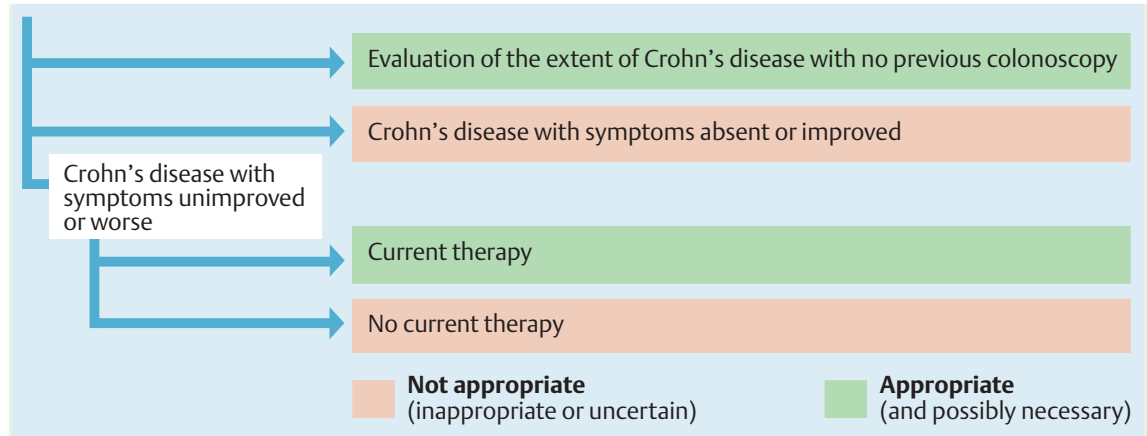

Fig. 3a Appropriateness ratings of clinical indications for performing colonoscopy in patients for the evaluation of known Crohn's disease, excluding surveillance for colorectal cancer (simplified decision tree). SBFT, small-bowel follow-through; CT/MRI, computed tomography/magnetic resonance imaging. Copyright $\odot 2008$ IUMSP/CHUV, Lausanne, Switzerland - EPAGE II. 


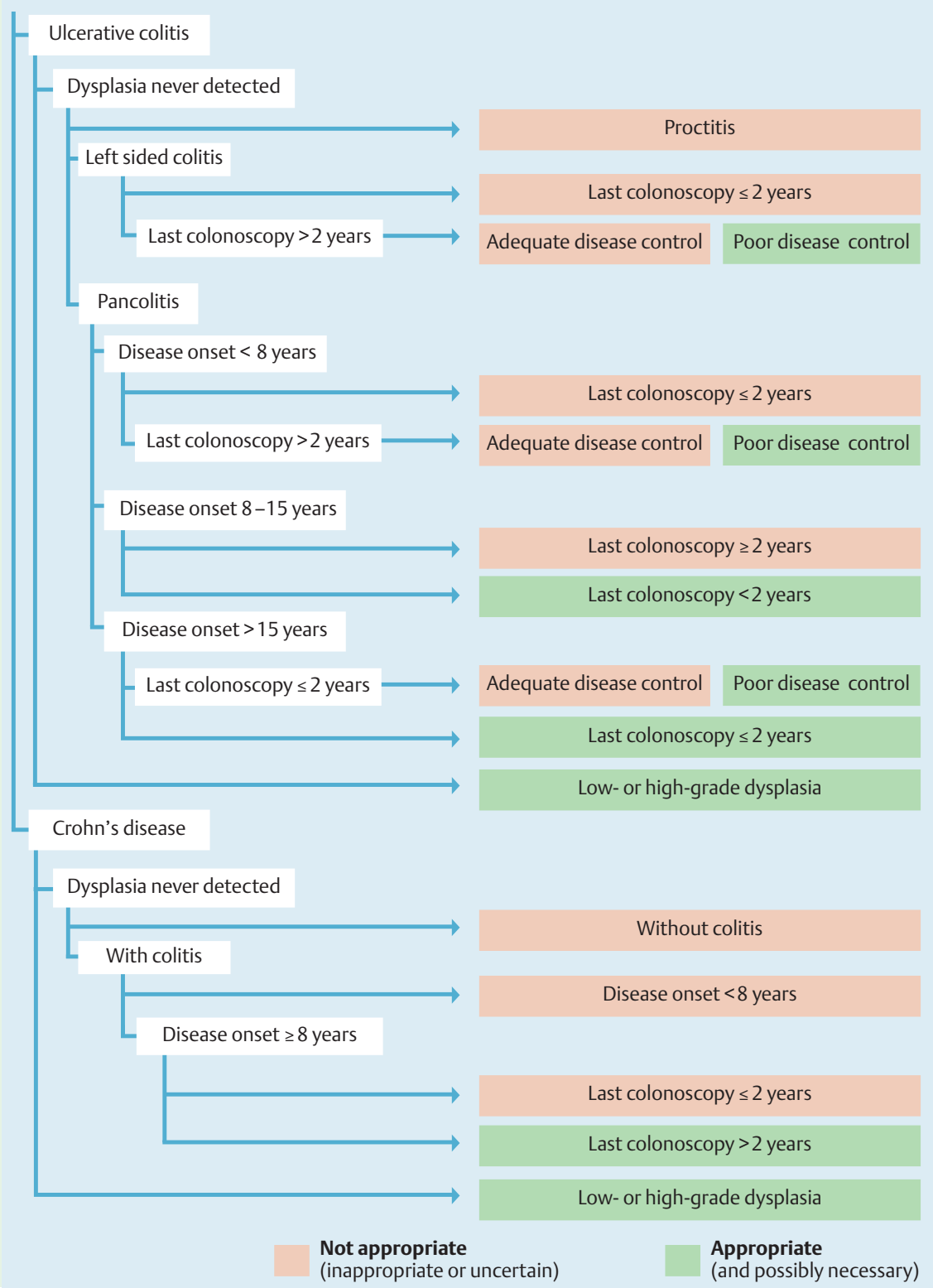

Fig. 4a Appropriateness ratings of clinical indications for performing colonoscopy for surveillance for colorectal cancer in patients with known inflammatory bowel disease (simplified decision tree). Copyright @ 2008 IUMSP/CHUV, Lausanne, Switzerland - EPAGE II.

lonoscopy in IBD patients ( $\bullet$ Fig.4a) was generally appropriate after a period of 2 years. In the presence of dysplasia at previous colonoscopy, it was not only appropriate but necessary (mandating colonoscopy). More detailed results presenting the four main categories of appropriateness (inappropriate, uncertain, appropriate, and both appropriate and necessary, that is, mandating colonoscopy) can be found online (Figs. e1b, e2b, e3b, e4b).

\section{Conclusions: Literature review}

$\nabla$

\section{Chronic diarrhea}

Caution is necessary in the interpretation of results from the literature on the appropriateness of colonoscopy for patients with chronic diarrhea. Primary studies are of modest quality. Most of them have a small sample size and are retrospective case series, without a control group. Variations in results can be explained by the heterogeneity existing in the studies in outcomes measured, study design, definitions, indications for colonoscopy, and/or inclusion criteria, thus reflecting the discrepancies in and the evolution of the definition of chronic diarrhea. Direct comparison of results between studies is therefore difficult and hence guidelines on this must be interpreted with caution, being mainly based on modest evidence, expert opinion, and consensus. The role of diagnostic colonoscopy thus remains uncertain but, if this procedure is performed and findings are macroscopically normal, multiple biopsies should be taken to exclude microscopic colitis.

The literature review also highlights the fact that despite the modest quality of evidence, and although the presence of these symptoms probably does not enhance the pick-up rate of CRC per se, recommendations tend to consider screening purposes together with clinical symptoms as an indication for performing an evaluation colonoscopy. Colonoscopic evaluation may thus be justified for patients aged $>50$ years with recent-onset chronic diarrhea or for any patients with such a complaint in association with alarm symptoms.

\section{Known IBD}

Assessment of the appropriateness of colonoscopy in management of known ulcerative colitis and Crohn's disease relies on modest evidence. Available primary studies in patients with 
known IBD are aimed at evaluating the efficiency of specific treatments, rather than the general impact of colonoscopy on patient outcome. Expert opinion and consensus play an important role in the recommendations on colonoscopy in $\operatorname{IBD}[45,98]$. Guidelines on the use of colonoscopy for surveillance in ulcerative colitis and Crohn's disease provide remarkably uniform recommendations, mostly relying on past studies [99] on CRC risk. The available evidence remains, however, modest. Considerable variation in the reported association between IBD and CRC might be due to differences in referral patterns, in follow-up, to differences in the methods of evaluating cancer risk, and to biological differences among the patients studied $[45,100]$. Surveillance of CRC in IBD has important limitations [98,100-102], including the possibility of a lead-time bias [100], limited patient compliance [103], variable endoscopic quality $[104,105]$, poor interobserver agreement in histopathological interpretation, and disagreement in the management of dysplasia [45]. Although knowledge on the risk of CRC in ulcerative colitis and Crohn's disease does reveal some discrepancies, guidelines issue similar surveillance recommendations for both IBDs.

The appropriateness of colonoscopy in the management of known ulcerative colitis and Crohn's disease is in many cases debatable and depends on the evolution of the disease and on the therapeutic approach. Colonoscopy is useful in the preoperative phase and in the therapeutic management of short accessible strictures and of bleeding. In the future, endoscopic procedures might be indicated and systematically performed in order to monitor mucosal healing in patients where biological treatments are planned and/or under way $[106,107]$. Literature data support CRC surveillance in IBD, while at the same time recognizing its limitations. In the future, new techniques such as endomicroscopy and chromoendoscopy might considerably improve detection procedures for colonic dysplasia $[108,109]$.

\section{Conclusions: EPAGE II panel}

The EPAGE II panel criteria confirmed the appropriateness of diagnostic colonoscopy for diarrhea of at least 4 weeks' duration. They also suggest that, in addition to assessing the extent of IBD by colonoscopy, further colonoscopic examination is appropriate in the face of persistent or worsening symptoms. The indication for surveillance colonoscopy in IBD patients is generally considered appropriate after a lapse of 2 years; in the presence of dysplasia at previous colonoscopy, it is not only appropriate but necessary.

\section{Acknowledgments \\ $\nabla$}

The authors gratefully acknowledge the selfless commitment and invaluable contribution of the expert panel members, who made this project possible: Lars Agréus (SE), Christoph Beglinger (CH), Peter Bytzer (DK), Michel Delvaux (FR), Volker F. Eckardt (DE), Peter D. Fairclough (UK), François Lacaine (FR), Olivier Le Moine (BE), Vicente Lorenzo Zúñiga Garcia (ES), Giorgio Minoli (IT), Mattijs E. Numans (NL), Daniel Oertli (CH), John O'Malley (UK), Alastair Windsor (UK). The authors warmly thank Susan Giddons for her invaluable assistance in the administration of the expert panel process, as well as in the meticulous preparation of the manuscripts.
This work was supported by a grant from the Loterie Romande (Switzerland).

Competing interests: None

\section{Appendix: The EPAGE II Study Group \\ $\nabla$}

See page 205 .

\section{Institutions}

1 Healthcare Evaluation Unit, Institute of Social and Preventive Medicine, University of Lausanne and Centre Hospitalier Universitaire Vaudois, Lausanne, Switzerland

2 Department of Gastroenterology and Hepatology, Centre Hospitalier Universitaire Vaudois and University of Lausanne, Lausanne, Switzerland

3 Department of Surgery, University College London Hospitals, London, United Kingdom

${ }^{4}$ Department of Gastroenterology, University of Basle, Basle, Switzerland

Cerner LifeSciences, Beverly Hills, USA

6 The EPAGE II Study Group*

\section{References}

1 Thomas PD, Forbes A, Green J et al. Guidelines for the investigation of chronic diarrhoea, 2nd edition. Gut 2003; 52 Suppl 5: v1 - v15

2 Fine KD, Schiller LR. AGA technical review on the evaluation and management of chronic diarrhea. Gastroenterology 1999; 116: 1464-1486

3 Bolin TD, Davis AE, Duncombe VM. A prospective study of persistent diarrhoea. Aust NZ J Med 1982; 12: 22 - 26

4 Bytzer P, Stokholm M, Andersen I et al. Aetiology, medical history, and faecal weight in adult patients referred for diarrhoea. A prospective survey. Scand J Gastroenterol 1990; 25: 572-578

5 Carter MJ, Lobo AJ, Travis SP. Guidelines for the management of inflammatory bowel disease in adults. Gut 2004; 53 Suppl 5: V1 - V16

6 Kornbluth A, Sachar DB. Ulcerative colitis practice guidelines in adults (update): American College of Gastroenterology, Practice Parameters Committee. Am J Gastroenterol 2004; 99: 1371 - 1385

7 D'Haens G, Sandborn WJ, Feagan BG et al. A review of activity indices and efficacy end points for clinical trials of medical therapy in adults with ulcerative colitis. Gastroenterology 2007; 132: 763-786

8 Henriksen M, Jahnsen J, Lygren I et al. Ulcerative colitis and clinical course: results of a 5-year population-based follow-up study (the IBSEN study). Inflamm Bowel Dis 2006; 12: 543-550

9 Stange EF, Travis SPL, Vermeire $S$ et al. European evidence based consensus on the diagnosis and management of Crohn's disease: definitions and diagnosis. Gut 2006; 55 Suppl 1: i1 -i15

10 Hanauer SB, Sandborn W. Management of Crohn's disease in adults. Am J Gastroenterol 2001; 96: 635-643

11 Gasche C, Scholmerich J, Brynskov J et al. A simple classification of Crohn's disease: report of the Working Party for the World Congresses of Gastroenterology, Vienna 1998. Inflamm Bowel Dis 2000; 6: 8-15

12 Satsangi J, Silverberg MS, Vermeire S et al. The Montreal classification of inflammatory bowel disease: controversies, consensus, and implications. Gut 2006; 55: 749-753

13 Silverberg MS, Satsangi J, Ahmad T et al. Toward an integrated clinical, molecular and serological classification of inflammatory bowel disease: Report of a Working Party of the 2005 Montreal World Congress of Gastroenterology. Can J Gastroenterol 2005; 19 Suppl A : 5-36

14 Best WR, Becktel JM, Singleton JW. Rederived values of the eight coefficients of the Crohn's Disease Activity Index (CDAI). Gastroenterology 1979; 77: $843-846$

15 Henriksen M, Jahnsen J, Lygren I et al. Clinical course in Crohn's disease: results of a five-year population-based follow-up study (the IBSEN study). Scand J Gastroenterol 2007; 42: 602-610

16 Silverstein MD, Loftus EV, Sandborn WJ et al. Clinical course and costs of care for Crohn's disease: Markov model analysis of a population-based cohort. Gastroenterology 1999; 117: 49-57

17 Konikoff MR, Denson LA. Role of fecal calprotectin as a biomarker of intestinal inflammation in inflammatory bowel disease. Inflamm Bowel Dis 2006; 12: 524-534

\footnotetext{
* See Appendix: The EPAGE II Study Group
} 
18 Leighton JA, Shen B, Baron TH et al. ASGE guideline: endoscopy in the diagnosis and treatment of inflammatory bowel disease. Gastrointest Endosc 2006; 63: $558-565$

19 Vader JP, Froehlich F, Juillerat P et al. Appropriate treatment for Crohn's disease: methodology and summary results of a multidisciplinary international expert panel approach - EPACT. Digestion 2006; 73: 237 248

20 Bernstein CN, Blanchard JF, Kliewer E et al. Cancer risk in patients with inflammatory bowel disease: a population-based study. Cancer 2001; 91: 854-862

21 Collins PD, Mpofu C, Watson AJ et al. Strategies for detecting colon cancer and/or dysplasia in patients with inflammatory bowel disease. Cochrane Database Syst Rev 2006; 2: CD000279

22 Eaden JA, Abrams KR, Mayberry JF. The risk of colorectal cancer in ulcerative colitis: a meta-analysis. Gut 2001; 48: 526-535

23 Gupta RB, Harpaz N, Itzkowitz S et al. Histologic inflammation is a risk factor for progression to colorectal neoplasia in ulcerative colitis: a cohort study. Gastroenterology 2007; 133: 1099-1105

24 Jess T, Gamborg M, Matzen P et al. Increased risk of intestinal cancer in Crohn's disease: a meta-analysis of population-based cohort studies. Am J Gastroenterol 2005; 100: 2724-2729

25 Jess T, Loftus EV jr., Velayos FS et al. Risk of intestinal cancer in inflammatory bowel disease: a population-based study from Olmsted County, Minnesota. Gastroenterology 2006; 130: 1039-1046

26 Jess T, Loftus EV, Velayos FS et al. Risk factors for colorectal neoplasia in inflammatory bowel disease: a nested case-control study from Copenhagen county, Denmark and Olmsted county, Minnesota. Am J Gastroenterol 2007; 102: 829-836

27 Karvellas CJ, Fedorak RN, Hanson J et al. Increased risk of colorectal cancer in ulcerative colitis patients diagnosed after 40 years of age. Can J Gastroenterol 2007; 21: 443-446

28 Lakatos L, Mester G, Erdelyi Z et al. Risk factors for ulcerative colitisassociated colorectal cancer in a Hungarian cohort of patients with ulcerative colitis: results of a population-based study. Inflamm Bowel Dis 2006; 12: 205-211

29 Siegel CA, Sands BE. Risk factors for colorectal cancer in Crohn's colitis: a case-control study. Inflamm Bowel Dis 2006; 12: 491 - 496

30 Soetikno RM, Lin OS, Heidenreich PA et al. Increased risk of colorectal neoplasia in patients with primary sclerosing cholangitis and ulcerative colitis: a meta-analysis. Gastrointest Endosc 2002; 56: 48 - 54

31 Thomas T, Abrams KA, Robinson RJ et al. Meta-analysis: cancer risk of low-grade dysplasia in chronic ulcerative colitis. Aliment Pharmacol Ther 2007; 25: 657-668

32 von Roon AC, Reese G, Teare J et al. The risk of cancer in patients with Crohn's disease. Dis Colon Rectum 2007; 50: 839-855

33 Hookman P, Barkin JS. What should be the standard care for cancer surveillance, diagnosis of dysplasia, and the decision for colectomy in chronic inflammatory bowel disease? Am J Gastroenterol 2002; 97: $1249-1255$

34 Rubin DT. The changing face of colorectal cancer in inflammatory bowel disease: progress at last! Gastroenterology 2006; 130: 1350-1352

35 Itzkowitz SH, Yio X. Inflammation and cancer IV. Colorectal cancer in inflammatory bowel disease: the role of inflammation. Am J Physiol Gastrointest Liver Physiol 2004; 287: G7-G17

36 Itzkowitz SH, Harpaz N. Diagnosis and management of dysplasia in patients with inflammatory bowel diseases. Gastroenterology 2004; 126: $1634-1648$

37 Askling J, Dickman PW, Karlen P et al. Family history as a risk factor for colorectal cancer in inflammatory bowel disease. Gastroenterology 2001; 120: 1356-1362

38 Geboes K. Review article: what are the important endoscopic lesions for detection of dysplasia in inflammatory bowel disease? Aliment Pharmacol Ther 2006; 24 Suppl 3: 50-55

39 Rubin DT, Rothe JA, Hetzel JT et al. Are dysplasia and colorectal cancer endoscopically visible in patients with ulcerative colitis?. Gastrointest Endosc 2007; 65: 998 - 1004

40 Rutter MD, Saunders BP, Wilkinson KH et al. Cancer surveillance in longstanding ulcerative colitis: endoscopic appearances help predict cancer risk. Gut 2004; 53: $1813-1816$

41 Bronner MP, Goldblum JR, Kimmey MB et al. Low-grade dysplasia in ulcerative colitis: natural history data still unknown. Gastroenterology 2004; 127: $362-363$

$42 \mathrm{Lim}$ CH, Dixon MF, Vail A et al. Ten year follow up of ulcerative colitis patients with and without low grade dysplasia. Gut 2003; 52: $1127-$ 1132
43 Rubio CA, Befrits R. Low-grade dysplasia in flat mucosa in ulcerative colitis. Gastroenterology 2004; 126: 1494-1495

44 Ullman T, Croog V, Harpaz N et al. Progression of flat low-grade dysplasia to advanced neoplasia in patients with ulcerative colitis. Gastroenterology 2003; 125: 1311 - 1319

45 Campbell S, Ghosh S. Ulcerative colitis and colon cancer: strategies for cancer prevention. Dig Dis 2002; 20: 38-48

46 Delco F, Sonnenberg A. The unsolved problem of surveillance for colorectal cancer in ulcerative colitis. Can J Gastroenterol 1999; 13: 655 660

47 Froehlich F, Larequi-Lauber T, Gonvers JJ et al. 11. Appropriateness of colonoscopy: inflammatory bowel disease. Endoscopy 1999; 31: 647 653

48 Gonvers JJ, Bochud M, Burnand B et al. 10. Appropriateness of colonoscopy: diarrhea. Endoscopy 1999; 31: 641 - 646

49 Longstreth GF, Thompson WG, Chey WD et al. Functional bowel disorders. Gastroenterology 2006; 130: 1480-1491

50 Juillerat P, Peytremann-Bridevaux I, Vader JP et al. Appropriateness of Colonoscopy in Europe (EPAGE II). Presentation of methodology, general results, and analysis of complications. Endoscopy 2008; 41: 240246

51 Adler A, Roll S, Marowski B et al. Appropriateness of colonoscopy in the era of colorectal cancer screening: a prospective, multicenter study in a private-practice setting (Berlin Colonoscopy Project 1, BECOP 1). Dis Colon Rectum 2007; 50: 1628 - 1638

52 Agnarsdottir M, Gunnlaugsson O, Orvar KB et al. Collagenous and lymphocytic colitis in Iceland. Dig Dis Sci 2002; 47: $1122-1128$

53 DeBosset V, Froehlich F, Rey JP et al. Do explicit appropriateness criteria enhance the diagnostic yield of colonoscopy? Endoscopy 2002; 34: $360-368$

54 Duncan JE, Sweeney WB, Trudel JL et al. Colonoscopy in the elderly: low risk, low yield in asymptomatic patients. Dis Colon Rectum 2006; 49: 646-651

55 Fernandez-Banares $F$, Salas A, Forne $M$ et al. Incidence of collagenous and lymphocytic colitis: a 5-year population-based study. Am J Gastroenterol 1999; 94: 418-423

56 Fine $K D$, Seidel $R H$, Do $K$. The prevalence, anatomic distribution, and diagnosis of colonic causes of chronic diarrhea. Gastrointest Endosc 2000; $51: 318-326$

57 Gonvers JJ, Harris JK, Wietlisbach V et al. A European view of diagnostic yield and appropriateness of colonoscopy. Hepatogastroenterology 2007; 54: 729-735

58 Lasson A, Kilander A, Stotzer PO. Diagnostic yield of colonoscopy based on symptoms. Scand J Gastroenterol 2008; 43: 356-362

59 Lieberman DA, de Garmo PL, Fleischer DE et al. Colonic neoplasia in patients with nonspecific GI symptoms. Gastrointest Endosc 2000; 51: $647-651$

60 Matteoni CA, Wang N, Goldblum JR et al. Flexible sigmoidoscopy for the detection of microscopic colitis. Am J Med 2000; 108: 416-418

61 Morini S, Hassan C, Meucci G et al. Diagnostic yield of open access colonoscopy according to appropriateness. Gastrointest Endosc 2001; 54: $175-179$

62 Offner FA, Jao RV, Lewin KJ et al. Collagenous colitis: a study of the distribution of morphological abnormalities and their histological detection. Hum Pathol 1999; 30: 451 - 457

63 Olesen M, Eriksson S, Bohr J et al. Microscopic colitis: a common diarrhoeal disease: an epidemiological study in Orebro, Sweden, 19931998. Gut 2004; 53: $346-350$

64 Pardi DS, Loftus EVjr., Smyrk TC et al. The epidemiology of microscopic colitis: a population based study in Olmsted County, Minnesota. Gut 2007; 56: 504-508

65 Patel Y, Pettigrew NM, Grahame GR et al. The diagnostic yield of lower endoscopy plus biopsy in nonbloody diarrhea. Gastrointest Endosc 1997; 46: 338 - 343

66 Shah RJ, Fenoglio-Preiser C, Bleau BL et al. Usefulness of colonoscopy with biopsy in the evaluation of patients with chronic diarrhea. Am J Gastroenterol 2001; 96: 1091 -1095

67 Yusoff IF, Ormonde DG, Hoffman NE. Routine colonic mucosal biopsy and ileoscopy increases diagnostic yield in patients undergoing colonoscopy for diarrhea. J Gastroenterol Hepatol 2002; 17: 276-280

68 Froehlich F, Gonvers JJ Diagnostic yield of colonoscopy by indication. In: Waye JD, Rex DK, Williams CB, (eds) Colonoscopy: principles and practice. London: Blackwell Science, 2003: 111-130

69 Pardi DS, Smyrk TC, Tremaine WJ et al. Microscopic colitis: a review. Am J Gastroenterol 2002; 97: 794-802 
70 Agence Nationale d'Accréditation et d'Evaluation en Santé. [Endoscopie digestive basse: indications en dehors du dépistage en population Argumentaire]. Saint-Denis La Plaine: Haute Autorité de Santé, 2004: 138p. Available from: http://www.has-sante.fr/portail/display.jsp? id=c_272348 [Accessed: 28-5-2007]

71 Australian Cancer Network Colorectal Cancer Guidelines Revision Committee. Guidelines for the prevention, early detection and management of colorectal cancer. Sydney: The Cancer Council Australia and Australian Cancer Network, 2005: 368p. ISSN 0-9775060-1-0. Available from: http://www.nhmrc.gov.au/publications/synopses/cp106/ files/cp106.pdf* [Accessed: 1 -6-2007]

72 Eisen GM, Dominitz JA, Faigel DO et al. Use of endoscopy in diarrheal illnesses. Gastrointest Endosc 2001; 54: 821 - 823

73 Rex DK, Petrini JL, Baron TH et al. Quality indicators for colonoscopy. Gastrointest Endosc 2006; 63: S16 - S28

74 Singapore Ministry of Health. Colorectal cancer. Report nr 2/2004 Singapore: 2004: 98p. Available from: http://www.hpp.moh.gov.sg/HPP/ MungoBlobs/145/831/2004\%20colorectalcancer_0.pdf [Accessed: 138-2007]

75 Beaugerie $L$. Place de l'endoscopie dans les colites microscopiques. 2003: 6p. Available from: http://www.sfed.org/documents_sfed/files/ recommandations/Endoscopie_colitesmicro.pdf [Accessed: 1-62007]

76 Kojima M, Wakai K, Tokudome S et al. Bowel movement frequency and risk of colorectal cancer in a large cohort study of Japanese men and women. Br J Cancer 2004; 90: 1397-1401

77 Kune GA, Kune S, Field B et al. The role of chronic constipation, diarrhea, and laxative use in the etiology of large-bowel cancer. Data from the Melbourne Colorectal Cancer Study. Dis Colon Rectum 1988; 31: $507-512$

78 Otani T, Iwasaki M, Inoue $M$ et al. Bowel movement, state of stool, and subsequent risk for colorectal cancer: the Japan public health centerbased prospective study. Ann Epidemiol 2006; 16: 888 - 894

79 American Cancer Society. Cancer facts and figures 2007. 2007: 56p. Available from: http://www.cancer.org/downloads/STT/CAFF2007PWSecured.pdf [Accessed: 8-11-2007]

80 Davila RE, Rajan E, Adler D et al. ASGE guideline: the role of endoscopy in the diagnosis, staging, and management of colorectal cancer. Gastrointest Endosc 2005; 61: 1-7

81 Davila RE, Rajan E, Baron TH et al. ASGE guideline: colorectal cancer screening and surveillance. Gastrointest Endosc 2006; 63: 546- 557

82 Institute for Clinical Systems Improvement (ICSI). Colorectal cancer screening. 11th Edition . Bloomington (MN): 2006: 51p. Available from: http://www.icsi.org/colorectal_cancer_screening/colorectal_cancer_screening_5.html [Accessed: 13-8-2007]

83 Levin B, Barthel J, Burt R et al. Practice guidelines in Oncology: Colorectal cancer screening. National Comprehensive Cancer Network, 2007 Available from: http://www.nccn.org/professionals/physician_gls/ PDF/colorectal_screening.pdf [Accessed: 8-11-2007

84 McLeod $R$ Canadian Task Force on Preventive Health Care. Screening strategies for colorectal cancer: systematic review and recommendations. Technical review. CTFPHC Technical Report nr 01-2. London, Ontario: Canadian Task Force on Preventive Health Care, 2001: 37p. Available from: http://www.ctfphc.org/ [Accessed: 8-11-2007]

85 National Guideline Clearinghouse. Colorectal cancer screening clinical practice guideline - NGC summary. Oakland (USA): Kaiser Permanente Care Management Institute, 2006: 16p. Available from: http://www. guidelines.gov/summary/summary.aspx?doc_id $=10847 \& \mathrm{nbr}=005662$ \&string=colon [Accessed: 9-11-2007]

86 Pignone MP, Rich M, Teutsch $S$ et al. Screening for colorectal cancer in adults. Rockville: Agency for Healthcare Research and Quality (AHRQ), 2002: 48p. Available from: http://www.ahrq.gov/downloads/ pub/prevent/pdfser/colocanser.pdf [Accessed: 18-5-2007]

87 Rex DK, Johnson DA, Lieberman DA et al. Colorectal cancer prevention 2000: screening recommendations of the American College of Gastroenterology. American College of Gastroenterology. Am J Gastroenterol 2000; 95: $868-877$

88 Winawer S, Fletcher R, Rex D et al. Colorectal cancer screening and surveillance: clinical guidelines and rationale - Update based on new evidence. Gastroenterology 2003; 124: 544-560

89 Beau P, Gay G, Arput J et al. Place de l'endocopie dans le bilan de la maladie de Crohn. Société Française d'Endoscopie Digestive, 2004: 6p. Available from: http://www.sfed.org/documents_sfed/files/recommandations/Endoscopie_Crohn.pdf [Accessed: 1 - 6-2007]
90 Hoffmann JC, Zeitz M, Bischoff SC et al. Diagnostik und Therapie der Colitis ulcerosa: Ergebnisse einer evidenzbasierten Konsensuskonferenz der Deutschen Gesellschaft fuer Verdauungs- und Stoffwechselerkrankungen zusammen mit dem Kompetenznetz chronisch entzuendliche Darmerkrankungen [Diagnosis and therapy of ulcerative colitis: results of an evidence based consensus conference by the German society of Digestive and Metabolic Diseases and the competence network on inflammatory bowel disease]. Z Gastroenterol 2004; 42: 979-1032

91 Hoffmann RM, Kruis W. Chronisch-entzuendliche Darmerkrankungen. 3rd ed. Stuttgart: Demeter, 2002 ISBN/ISSN 3-13-1155930. Available from: http://www.dgvs.de/media/3.3.CED.pdf [Accessed: 24-9-2007]

92 Schreiber S, Folsch UR. Klinische Diagnostik, Klassification [Clinical diagnostics, classification]. Z Gastroenterol 2003; 41: 21 - 23

93 Barthet M, Gay G, Sautereau D et al. Surveillance endoscopique des maladies inflammatoires digestives. Société Française d'Endoscopie Digestive, 2004: 6p Available from: http://www.sfed.org/documents_sfed/files/recommandations/Surveillendo_MICI.pdf [Accessed: $27-5-2007]$

94 Eaden JA, Mayberry JF. Guidelines for screening and surveillance of asymptomatic colorectal cancer in patients with inflammatory bowel disease. Gut 2002; 51 Suppl 5: V10-V12

95 Heresbach $D$, Boyer J, Laugier $R$ et al. Techniques et indications des biopsies lors de la coloscopie. Société Française d'Endoscopie Digestive, 2007: 8p. Available from: http://www.sfed.org/documents_sfed/files/recommandations/Biopsie_coloscopie.pdf [Accessed: 1-6-2007]

96 Itzkowitz SH, Present DH. Consensus conference: Colorectal cancer screening and surveillance in inflammatory bowel disease. Inflamm Bowel Dis 2005; 11: 314- 321

97 Stange EF, Schreiber S, Folsch UR et al. Crohn-Ergebnisse einer evidenzbasierten Konsensuskonferenz der Deutschen Gesellschaft fuer Verdauungs- und Stoffwechselkrankheiten [Diagnostics and treatment of Crohn's disease - results of an evidence-based consensus conference of the German Society for Digestive and Metabolic Diseases]. Z Gastroenterol 2003; 41: 19-20

98 Ahmadi AA, Polyak S. Endoscopy/surveillance in inflammatory bowel disease. Surg Clin N Am 2007; 87: 743 - 762

99 Morson BC, Pang LS. Rectal biopsy as an aid to cancer control in ulcerative colitis. Gut 1967; 8: 423-434

100 Provenzale D, Onken J. Surveillance issues in inflammatory bowel disease: ulcerative colitis. J Clin Gastroenterol 2001; 32: 99-105

101 Delco F, Sonnenberg A. A decision analysis of surveillance for colorectal cancer in ulcerative colitis. Gut 2000; 46: 500-506

102 Vleggaar FP, Lutgens MW, Claessen MM. Review article: The relevance of surveillance endoscopy in long-lasting inflammatory bowel disease. Aliment Pharmacol Ther 2007; 26 Suppl 2: 47-52

103 Riegler G, Bossa F, Caserta L et al. Colorectal cancer and high grade dysplasia complicating ulcerative colitis in Italy. A retrospective cooperative IG-IBD study. Dig Liver Dis 2003; 35: 628 - 634

104 Rex DK, Cutler CS, Lemmel GT et al. Colonoscopic miss rates of adenomas determined by back-to-back colonoscopies. Gastroenterology 1997: $112: 24-28$

105 Toruner M, Harewood GC, Loftus EV jr. et al. Endoscopic factors in the diagnosis of colorectal dysplasia in chronic inflammatory bowel disease. Inflamm Bowel Dis 2005; 11: 428-434

106 Geboes K, Rutgeerts P, Opdenakker G et al. Endoscopic and histologic evidence of persistent mucosal healing and correlation with clinical improvement following sustained infliximab treatment for Crohn's disease. Curr Med Res Opin 2005; 21: 1741 - 1754

107 Rutgeerts P, Vermeire S, VanAssche G. Mucosal healing in inflammatory bowel disease: impossible ideal or therapeutic target? Gut 2007; 56: $453-455$

108 Brown S, Baraza W, Hurlstone P. Chromoscopy versus conventional endoscopy for the detection of polyps in the colon and rectum. Cochrane Database Syst Rev 2007; 4: CD006439

109 Thorlacius $H$, Toth E. Role of chromoendoscopy in colon cancer surveillance in inflammatory bowel disease. Inflamm Bowel Dis 2007; 13: $911-917$

110 Hassan C, Zullo A, de Francesco Vet al. Systematic review: Endoscopic dilatation in Crohn's disease. Aliment Pharmacol Ther 2007; 26: $1457-1464$ 
The following figures and tables are available online: www.thieme-connect.com/media/endoscopy/200903/supmat/ endo843.pdf

Fig. e1b Appropriateness ratings of clinical indications for performing colonoscopy in patients with uncomplicated chronic diarrhea (full decision tree).

Fig. e2b Appropriateness ratings of clinical indications for performing colonoscopy in patients for the evaluation of known ulcerative colitis, excluding surveillance for colorectal cancer (full decision tree).

Fig. e3b Appropriateness ratings of clinical indications for performing colonoscopy in patients for the evaluation of known Crohn's disease, excluding surveillance for colorectal cancer (full decision tree). SBFT, small-bowel follow through; CT/MRI, computed tomography/magnetic resonance imaging.

Fig. e4b Appropriateness ratings of clinical indications for performing colonoscopy for surveillance for colorectal cancer in patients with known inflammatory bowel disease (full decision tree).

Table e1 Studies investigating the diagnostic yield of colonoscopy in chronic diarrhea (1997 - February 2008).

Table e2 Guidelines on the appropriateness of diagnostic colonoscopy in chronic diarrhea.

Table e3 Studies investigating the association between diarrhea and colorectal cancer (CRC), 1997 - February 2008.

Table e4 Guidelines/reviews on the appropriateness of colonoscopy for the clinical management of known ulcerative colitis.

Table e5 Guidelines/reviews on the appropriateness of colonoscopy for the clinical management of known Crohn's disease.

Table e6 Guidelines/reviews on the use of colonoscopic surveillance for colorectal cancer (CRC) in patients with inflammatory bowel disease (IBD).

Table e7 Meta-analyses, reviews, and studies investigating the association between inflammatory bowel disease (IBD) and colorectal cancer (CRC) (1997 - February 2008). 